$\S=-1$

\title{
Optimal Sizing of UPQC to Mitigate Power Quality Issues Using ANF Controller
}

\author{
Senthil Vadivu U..$^{*}$, B.K. Keshavan ${ }^{2}$ \\ ${ }^{1}$ Department of Electrical and Electronics Engineering, PES University, Bangalore, India. \\ ${ }^{2}$ Department of Electrical and Electronics Engineering, PES University, Bangalore, India. \\ *Corresponding author E-mail: senthilv@pes.edu
}

\begin{abstract}
A design of compact converter based Unified Power Quality Conditioner (UPQC) is proposed to alleviate the power quality issues on both linear and non-linear load by means of a four switch three phase series and shunt converter with DC link capacitor. DC-link voltage regulation is obtained by Photovoltaic based boost converter. The recommended four switch converter system not only reduces the switching losses but also the cost of the converter as well as it reduces the number of active elements. Balancing of capacitors leg, filters and transformer are chosen based on the amount of sag and swell magnitude. The proposed scheme is implemented using sinusoidal pulse width modulation, simple space vector pulse width modulation and PI-Fuzzy control strategy to verify power quality issues like sag, swell and harmonics compensation added with the control performances. The performance of the optimized system is validated through simulations using MATLAB/SIMULINK.
\end{abstract}

Keywords: Adaptive Neuro Fuzzy (ANF); PI-Fuzzy Control Strategy; Power Quality (PQ); Self Tuned PID Controller, Unified Power Quality Conditioner (UPQC); Wind Energy Conversion System (WECS).

\section{Introduction}

The modern power system suffers from a huge power quality issues due to the vast implementation of power electronic devices. There are many conventional devices are used to improve and control the power quality problems such as STATCOM, SSSC, DVR, SVC etc. The multiple power quality issues are difficult to control in classical active filters schemes. Thus, in order to improve the power quality at both source side and load side a Unified Power Quality Conditioner (UPQC) is introduced.

Unified power quality conditioner combines the performances of STATCOM and DVR to inject power over Distribution line. To maintain the electric power quality well within the standard specified limit in the modern distribution system. Implementation of active filter plays a major role, which are connected back to back with a dc-link capacitor and it is named as UPQC [1]. This is widely used at the power distribution system to mitigate the power quality issues.

The UPQC is designed to perform both series and parallel active power compensation. To ensure the less steady state error the controlled sinusoidal quantities can be put into synchronous reference frame [2]. This would felicitate series-parallel power line condition. The use of unified power quality conditioner is manifested in various applications including critical load in power system such as induction furnaces. The major objective of series active filter is to provide a harmonic isolation among a transmission and a distribution system. The shunt active filter is used to alleviate the current harmonics and also it compensates the reactive power [3]. Moreover, it regulates the dc-link voltage among the filters.

There are many configurations of UPQC which are named due to its specific functions. As the series inverter simultaneously com- pensates active and reactive power, it is named as UPQC-S. This topology of UPQC maintains a desired source voltage in spite of sag/swell [4]. In some configurations the function of filters deviates from conventional UPQC based on the application. In this paper, shunt filter controls the voltage issues and series filter controls current issues. The major advantage is that, it does not need any coordinate transformation and also it can be used for low voltage applications. There are many control techniques are used to enhance the functions of the power conditioner [5]. An adaptive filter algorithm and a fuzzy logic controller is used extract the reference signals from supply voltage and load current.

\section{Proposed Optimized Converter System based UPQC}

The Fig. 1 shows the unified power quality conditioner system using reactive power compensation based reference current generation with four switch configuration and multi-converter system to improve the performance of distribution system at various load conditions. This paper introduces a four-switch three-phase converter which is used for both series and shunt converter to enhance the power quality at the source and load side to reduce the switching losses of converter system. The main drawback of phase balancing in Four-switch circuit configuration has overcome by introducing an adaptive Self-tuned PID using neuro-fuzzy logic control, an adaptive reference current generation scheme as well as PI-Fuzzy Control strategy. The proposed adaptive self-tuning PID using neuro-fuzzy logic controller is applied on DC-link capacitor for power balancing control and to improve sag and swell compensation with better angle control via shunt and series converter performance [6]. The passive component design is introduced to provide additional improvements in sag, swell and har- 
monics mitigation analysis [7]. The presented circuit and control configuration is tested using MATLAB/SIMULINK software.

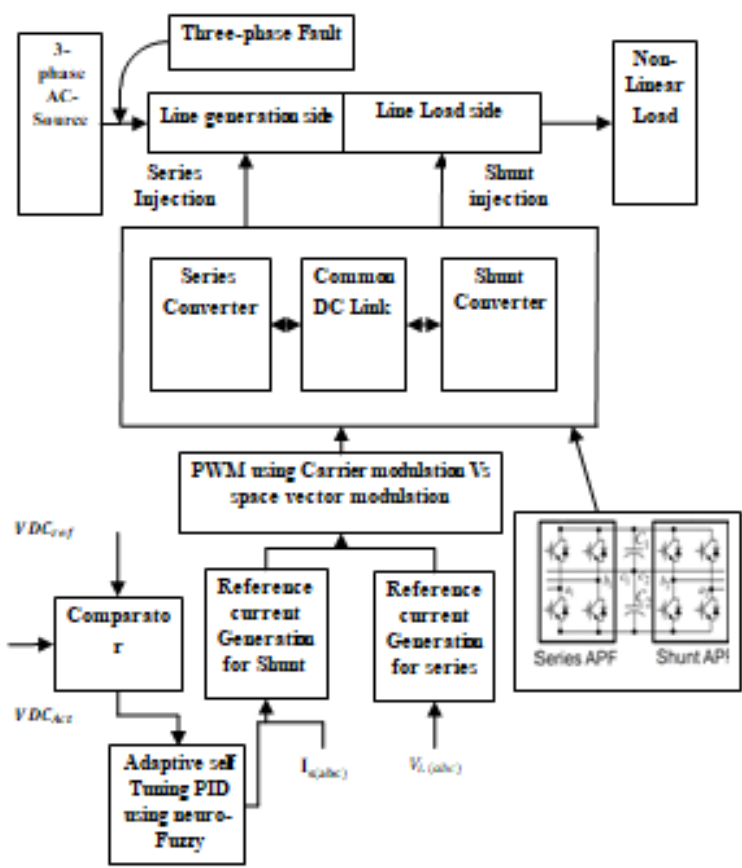

Fig. 1: Structure of proposed compact converter system for UPQC.

In the above block diagram, space vector pulse width modulation and carrier modulation schemes are compared together for voltage sag, voltage swell and harmonics mitigation. In both carrier and space vector PWM dc-link voltage is controlled by self-tuning of PID using neuro-fuzzy controller. Further, the behavior of the above stated system is also analyzed when supported with the novel PI-Fuzzy control strategy.

\subsection{Space Vector Modulation to Generate Control Puls-} es

The Space Vector Modulation (SVM) is the method of converting three phase quantities into two space vector quantities and hence it will be converted into polar form [8]. The SVPWM generates the pulses of the following:

- It accomplishes much wider linear modulation

- It reduces Total Harmonic Distortion

- It achieves minimum computational calculations

- It reduces switching losses

This method is applicable for output voltage and input current. It is more advantageous under unbalanced condition. Initially three phase quantities will be expressed in terms of space vectors, with in minimum time interval the reference vectors will be generated by means of stationary vectors generated with the help of matrix converter. By keeping this as a reference, the space vector rotates to a next angular position at the next sampling time. By continuing this required voltage vector would be synthesized.

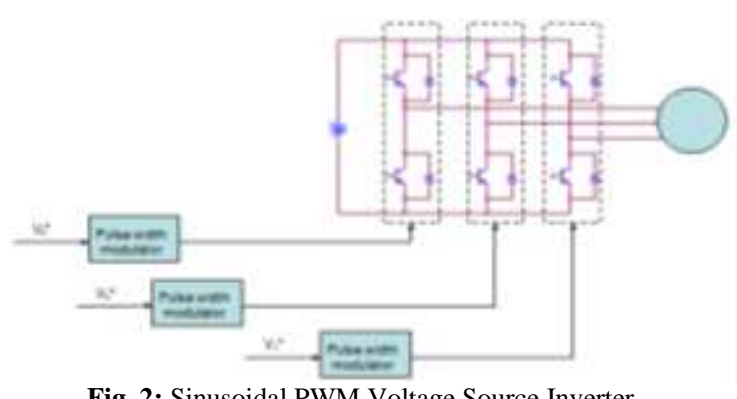

Fig. 2: Sinusoidal PWM Voltage Source Inverter.
It is necessary to generate $\mathrm{V}_{\text {ref }}, \mathrm{V}_{\mathrm{d}}, \mathrm{V}_{\mathrm{q}}$ and the angle $\alpha$, switching time of each switch in the inverter.

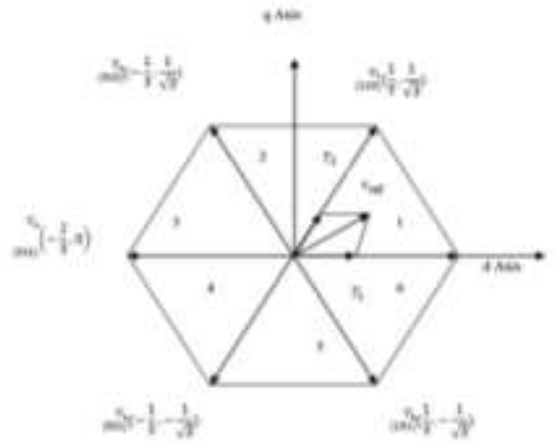

Fig. 3: Space Vector with different sectors.

The eight space vectors are transformed into required $V_{\text {ref }}$ by means of d-q plane using the following matrix.

$$
\left[\begin{array}{l}
V_{\mathrm{d}} \\
\mathrm{V}_{\mathrm{q}}
\end{array}\right]=\frac{2}{3}\left[\begin{array}{ccc}
1 & -\frac{1}{2} & -\frac{1}{2} \\
0 & \frac{\sqrt{3}}{2} & -\frac{\sqrt{3}}{2}
\end{array}\right]\left[\begin{array}{l}
\mathrm{V}_{\mathrm{an}} \\
\mathrm{V}_{\mathrm{bn}} \\
\mathrm{V}_{\mathrm{cn}}
\end{array}\right]
$$

$\mathrm{V}_{\text {ref }}=\operatorname{sqrt}\left(\mathrm{V}_{\mathrm{d}}^{2}+\mathrm{V}_{\mathrm{q}}^{2}\right)$

Hence, space vector quantities are generalized by the above equations.

\subsection{Cascade PI-Fuzzy Controller to Generate Control Pulses}

The simulated executable structure of a novel approach of PIFuzzy control strategy is depicted in the Fig. 4. It consists of a PI controller cascaded with the Fuzzy Logic Controller (FLC) (represented as a green colored blocks).

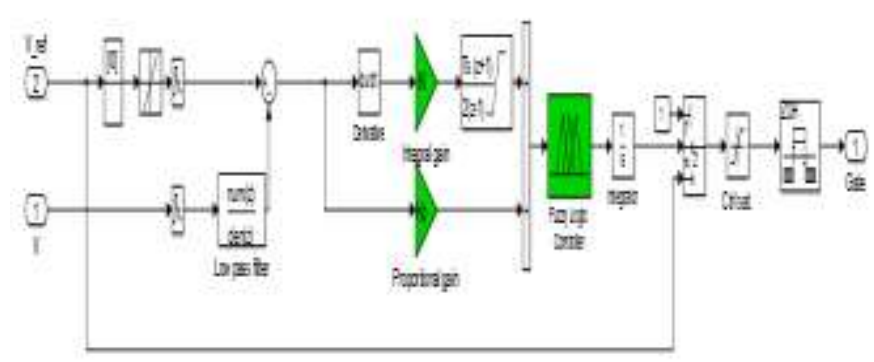

Fig. 4: Simulation structure of Cascade PI-Fuzzy control strategy.

The complete structure of a FLC is composed of Fuzzification, Inference engine, Defuzzification blocks.

The process of converting input/output variable to linguistic labels is termed as fuzzification. In the proposed paper, seven classes of linguistic labels namely: Large Positive (LP), Medium Positive (MP), Small Positive (SP), Zero (ZE), Small Negative (SN), Medium Negative (MN), Large Negative (LN) characterized by membership grade are used, to decompose each system variable into fuzzy regions having the range [-1 1$]$.

Inference Engine: The behavior of the FLC, relating the input and output variables of the system is governed by a set of rules. These rules relating the error and its rate of change are represented in Table 1. Based on this table, 49 rules are formed called as the Knowledge repository of the FLC. 


\begin{tabular}{|c|c|c|c|c|c|c|c|c|}
\hline \multicolumn{9}{|c|}{ Rate of change of error } \\
\hline \multirow{8}{*}{ Error } & & LP & $\mathbf{M P}$ & SP & $\mathbf{Z E}$ & SN & MN & LN \\
\hline & LN & $2 \mathrm{ZE}$ & SP & MP & MP & LP & LP & LP \\
\hline & MN & $\mathrm{SN}$ & ZE & SP & MP & MP & MP & LP \\
\hline & SN & $\mathrm{MN}$ & SN & $\mathrm{ZE}$ & SP & sp & MP & LP \\
\hline & 7.F. & $\mathrm{MN}$ & $\mathrm{MN}$ & SN. & $7 \mathrm{~F}$. & $\mathrm{sp}$ & MP & MP \\
\hline & SP & LN & $\mathrm{MN}$ & SN & $\mathrm{SN}$ & ZE & SP & MP \\
\hline & MP & $\mathrm{LN}$ & $\mathrm{MN}$ & $\mathrm{MN}$ & $\mathrm{MN}$ & SN & $Z E$ & SP \\
\hline & L.P & LN & LN & LN & MN & $\mathrm{MN}$ & SN & $\mathrm{ZE}$ \\
\hline
\end{tabular}

Defuzzification: The fuzzy set representing the controller output in linguistic labels has to be converted into a Crisp solution variable before it can be used to control the system. This is achieved by using a defuzzifier block.

\subsection{Modelling of Photovoltaic Array}

In this paper a Photovoltaic fed boost converter system is implemented for DC-link capacitor to supply current during fault conditions. The Proposed photovoltaic is developed using mathematical modeling of single diode model [9]. The equivalent circuit of a single diode model is shown in Fig. 5.

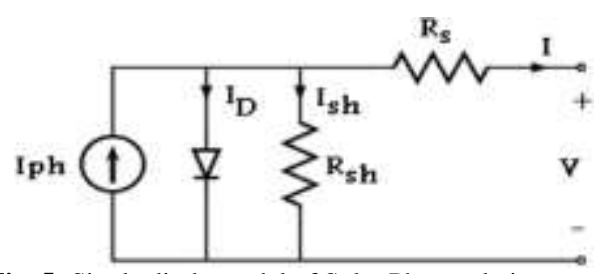

Fig. 5: Single diode model of Solar Photovoltaic system.

The V-I characteristics of photovoltaic cell can be obtained by the following equaitons:

Module current $\left(\mathrm{I}_{\mathrm{ph}}\right)$ :

$\mathrm{I}_{\mathrm{ph}}=\left[\mathrm{I}_{\mathrm{scr}}+\mathrm{K}_{\mathrm{i}}(\mathrm{T}-298)\right] \mathrm{G} / 100$

Reverse saturation current $\left(\mathrm{I}_{\mathrm{rs}}\right)$ :

$\mathrm{I}_{\mathrm{rs}}=\mathrm{I}_{\mathrm{sc}} /\left[\exp \left(\mathrm{q} * \mathrm{~V}_{\mathrm{oc}} / \mathrm{N}_{\mathrm{s}} \mathrm{KnT}\right)-1\right]$

Saturation current (Io):

$\mathrm{I}_{\mathrm{o}}=\mathrm{I}_{\mathrm{rs}}\left[\mathrm{T} / \mathrm{T}_{\mathrm{r}}\right] 3 \exp \left[\mathrm{q} * \mathrm{E}_{\mathrm{go}} / \mathrm{nK}\left(1 / \mathrm{T}-1 / \mathrm{T}_{\mathrm{r}}\right)\right]$

Output current of Photovoltaic cell (Ic):

$\mathrm{I}=\mathrm{N}_{\mathrm{ph}} * \mathrm{I}_{\mathrm{ph}}-\mathrm{N}_{\mathrm{p}} * \mathrm{I}_{\mathrm{o}} *\left[\exp \left(\mathrm{V} / \mathrm{N}_{\mathrm{s}}+\mathrm{I}^{*} \mathrm{R}_{\mathrm{s}} / \mathrm{N}_{\mathrm{p}} / \mathrm{n}^{*} \mathrm{~V}_{\mathrm{t}}\right)-1\right]-\mathrm{I}_{\mathrm{sh}}$

The photovoltaic cell is connected to the inverter through a dc-dc inverter. Voltage absorption and injection is obtained in DC-Link capacitor voltage by controlling pulse width modulation with respect to supply side fault across current. Power injection is taken while swell fault is appear whereas power absorption is taken while sag fault is appear using circuit breaker and DC-link power flow control. Same system configuration is utilized for both types of fault conditions with different tuning of transformer and DClink power flow control. Self-tuning of neuro fuzzy logic control is used to regulate the direct axis reference current and it act as a filters when faults appear on supply and line on proposed distribution system. This reference current is applied for adequate firing pulse generation using space vector modulation.

\section{Results and Discussions}

The four switch shunt and series converter system using split capacitor based common DC-link and alternative phase arrangement is implemented in this paper. The system is supplied by grid inter- faced based PMSG-Wind power is having capacity of $13 \mathrm{~kW}$. Voltage sag and swell fault is crated on wind phase power by creating faults on three -phase grid power source. The amount and depth of sag and swell fault basis, the amount power injection and absorption is taken in account using proposed converter operation using proposed control topologies. Series converter is act as voltage source converter whereas shunt converter is act as current source converter. Series converter scheme is used to control of faults in initial form of conversion. Shunt conversion is used to control of fault by injection and absorption of load faults and load side harmonics, as in the Fig. 6.

Proposed system was tested under sag and swell voltage faults on both linear as well as non-linear conditions. Amount of sag, swell voltage compensation is purely based on transformer tuning, DClink voltage control and shunt-series converter operation. Percentage of sag and swell we applied across supply terminals is $20 \%$.

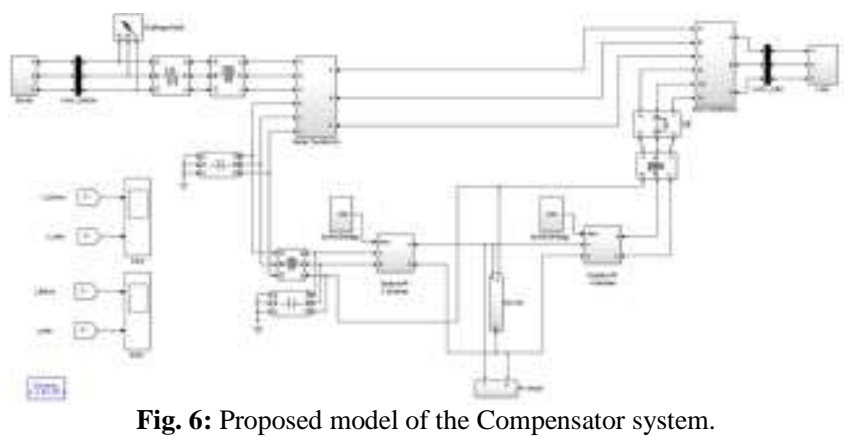

\subsection{Voltage Sag in Balanced Condition}

The voltage sag with sine PWM is analyzed under balanced condition and the voltage and current is generated as shown in Fig.7. It is observed that, the amplitude of supply voltage is decreased about $25 \%$ from its nominal voltage. Using an optimal converter system based UPQC adaptive reference current generation scheme using neuro-fuzzy logic control, the voltage sag is compensated and its performance is explained.

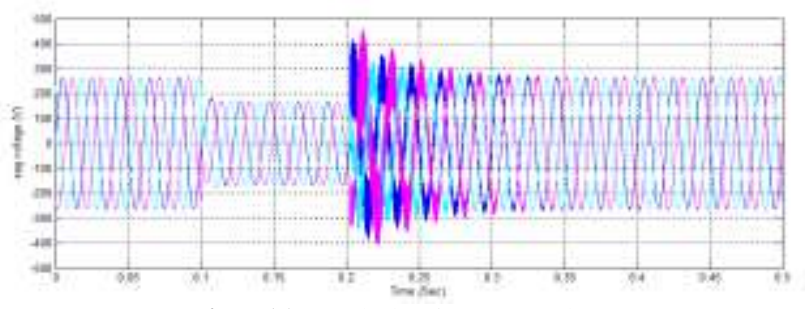

Fig. 7 (a): Analysis of Source Voltage.

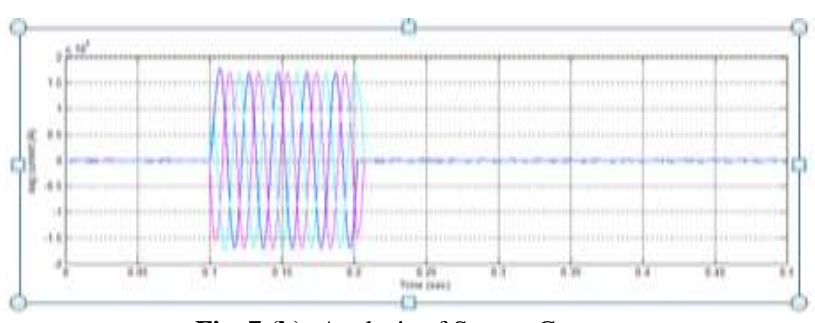

Fig. 7 (b): Analysis of Source Current.

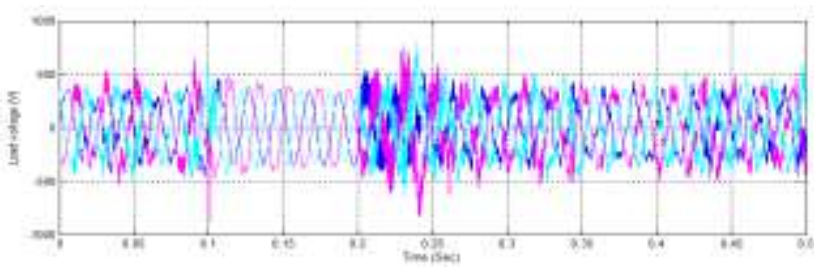

Fig. 8 (a): Analysis of Load Voltage. 


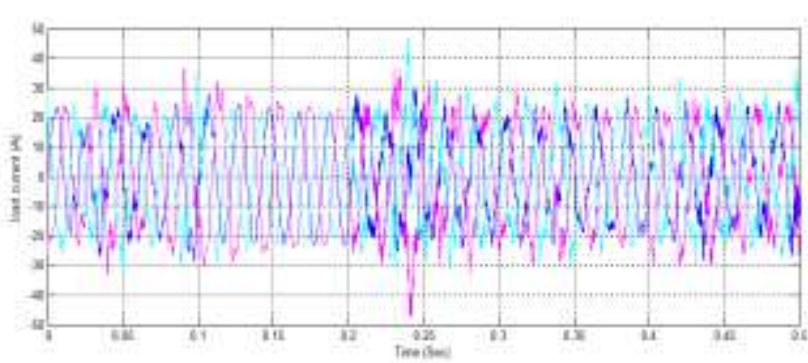

Fig. 8 (b): Analysis of Load Current.

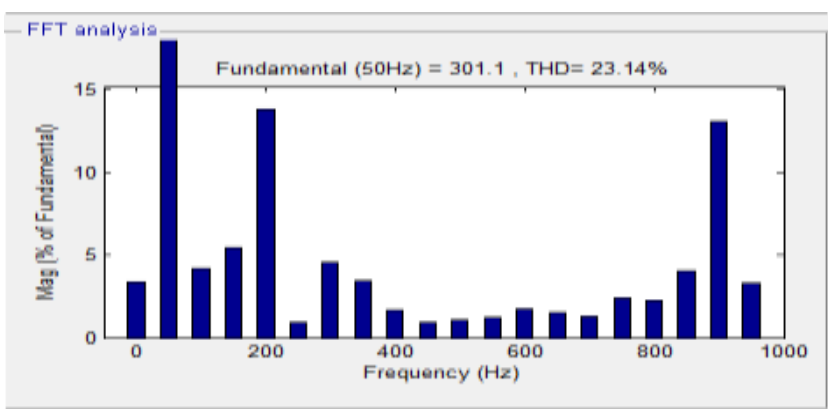

Fig. 9 (a): LHD analysis of Load Voltage using Carrier PWM.

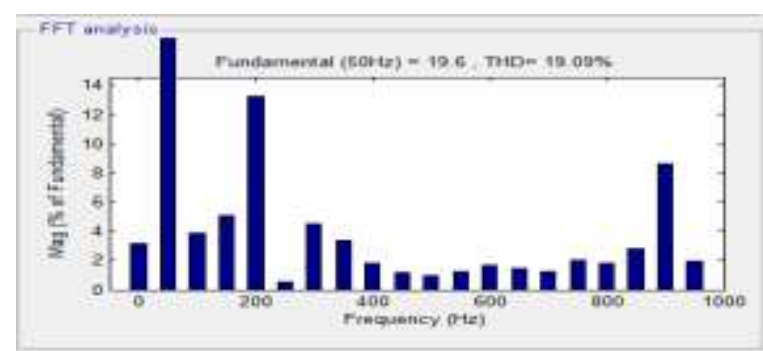

Fig. 9 (b): LHD analysis of Load Current using Carrier PWM.

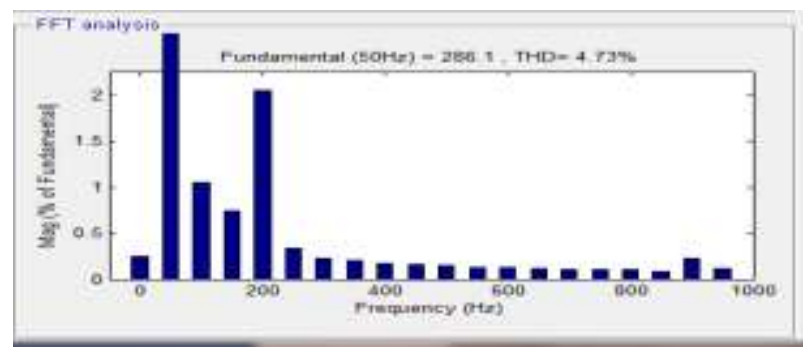

Fig. 10 (a): LHD analysis of Load Voltage using SVPWM.

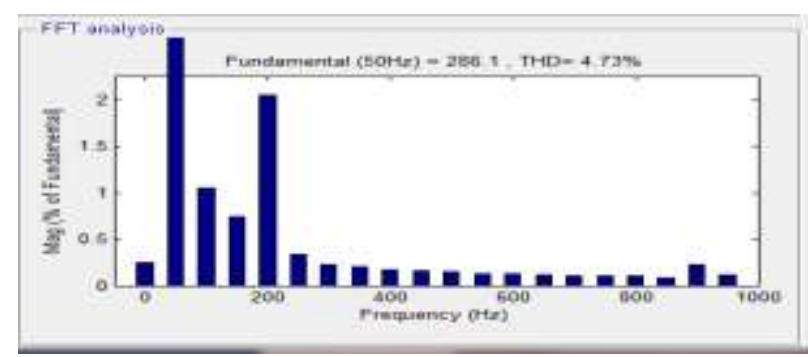

Fig. 10 (b): LHD analysis of Load Current using SVPWM.

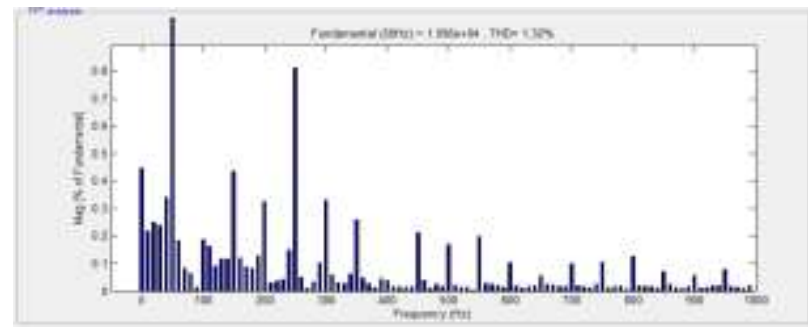

Fig. 11 (a): LHD analysis of Load Voltage using proposed PI-Fuzzy Control Strategy.

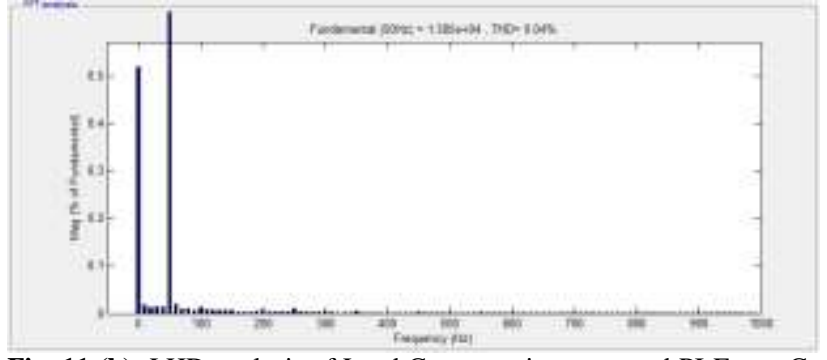

Fig. 11 (b): LHD analysis of Load Current using proposed PI-Fuzzy Control Strategy.

As it observed from the results, the load voltage and load current are kept at the nominal value with the help of a control algorithm based UPQC, as depicted in Fig. 8. When compared with other techniques, the voltage/current is compensated more efficiently with respect to time by given proposed methodologies.

The Fig. 9 shows the FFT analysis of load voltage and load current when compensated using carrier PWM approach. Next to that, Fig. 10 represents the FFT analysis of load voltage and load current resulted when compensated using the proposed SVPWM technique. Proceeding to these, the Fig. 11 depicts FFT analysis of load voltage and load current resulted when compensated by utilizing the features of novel PI-Fuzzy control strategy.

\subsection{Comparative Analysis of the Proposed Methods}

The efficiency of the projected methodology is compared with GA supported UPQC regulator and ANFIS supported UPQC regulator and further with the PI-Fuzzy methodology supported UPQC regulator.

Table 2: Comparison of Carrier PWM, SVPWM and PI-Fuzzy Methods in Sag Compensation.

\begin{tabular}{|l|l|l|l|l|}
\hline $\begin{array}{l}\text { Sl. } \\
\text { No }\end{array}$ & Content & $\begin{array}{l}\text { Carrier } \\
\text { PWM }\end{array}$ & SVPWM & PI-FUZZY \\
\hline 1 & $\begin{array}{l}\text { Source voltage } \\
\text { THD \% }\end{array}$ & 4.47 & 4.41 & 10.36 \\
\hline 2 & $\begin{array}{l}\text { Source Current } \\
\text { THD \% }\end{array}$ & 7.15 & 1.18 & 4.41 \\
\hline 3 & $\begin{array}{l}\text { Load Voltage } \\
\text { THD \% }\end{array}$ & 23.14 & 4.73 & 1.32 \\
\hline 4 & $\begin{array}{l}\text { Load Current } \\
\text { THD \% }\end{array}$ & 19.09 & 4.73 & 0.04 \\
\hline
\end{tabular}

\section{Conclusion}

The four switch shunt and series converter system using split capacitor based common DC-link and alternative phase arrangement is implemented in this paper. The system is supplied by grid interfaced based PMSG-Wind power is having capacity of $13 \mathrm{~kW}$. Voltage sag and swell fault is crated on wind phase power by creating faults on three -phase grid power source. Amount of sag, swell voltage compensation is purely based on transformer tuning, DC-link voltage control and shunt-series converter operation. Percentage of sag and swell we applied across supply terminals is $20 \%$. The THD values of load voltage and supply current is maintained as per the IEEE standards. Further, a clear comparison has been done among the proposed control strategies. And also, as the number of the switching devices is less, this topology can be effectively used for medium and high voltage distribution systems.

\section{References}

[1] V. Khadkikar, "Enhancing electric power quality using UPQC: comprehensive overview," IEEE Trans. Power Electron., vol. 27, no. 5, pp. 2284-2297, 2012.

[2] R. Modesto, S. da Silva, A. de Oliveira, and V. Bacon, "Versatile Unified Power Quality Conditioner Applied to a Three-Phase FourWire Distribution Systems Using a Dual Control Strategy," IEEE 
Trans. Power Electron., vol. 8993, no. c, pp. 1-1, 2015

[3] A. Vahabzadeh, H. Vadizadeh, F. A. Asl, and F. Kadkhoda, "Use of unified power quality conditioner in Khoozestan- Iran steel complex network, a case study," INTELEC, Int. Telecommun. Energy Conf., 2009

[4] R. J. M. Dos Santos, M. Mezaroba, and J. C. Da Cunha, "A dual unified power quality conditioner using a simplified control technique," COBEP 2011 - 11th Brazilian Power Electron. Conf. vol. 61, no. 11, pp. 486-493, 2011.

[5] A. Teke, L. Saribulut, and M. Tumay, "A novel reference signal generation method for power-quality improvement of unified power-quality conditioner," IEEE Trans. Power Deliv., vol. 26, no. 4, pp. 2205-2214, 2011

[6] S. B. Karanki, N. Geddada, M. K. Mishra, and B. K. Kumar, "A modified three-phase four-wire UPQC topology with reduced DC link voltage rating," IEEE Trans. Ind. Electron., vol. 60, no. 9, pp. 3555-3566, 2013.

[7] M. Hembram, "Mitigation of Power Quality Problems using Unified Power Quality Conditioner ( UPQC )," 2015.

[8] D. O. Neacsu, "Space Vector Modulation - An Introduction," IEEE Annu. Conf. Ind. Electron. Soc., vol. 0, no. 2, pp. 1583-1592, 2001.

[9] E. I. Banu, P. Eng, and M. Istrate, "Modeling and simulation of photovoltaic arrays MODELING AND SIMULATION OF PHOTOVOLTAIC ARRAYS," vol. 2012, no. JUNE 2012, pp. 1244-1254,2015 